\title{
Involvement of the Dorsal Striatum in Cue-Controlled Cocaine Seeking
}

\author{
Louk J. M. J. Vanderschuren, Patricia Di Ciano, and Barry J. Everitt \\ Department of Experimental Psychology, University of Cambridge, Cambridge CB2 3EB, United Kingdom
}

Through association with the interoceptive effects of drugs of abuse, neutral environmental stimuli can gain motivational properties themselves, becoming conditioned reinforcers that can evoke craving and relapse to drug seeking. Nucleus accumbens dopamine (DA) neurotransmission plays an important role in the reinforcing effect of cocaine itself, but, unlike nucleus accumbens glutamate, it seems not to mediate the conditioned reinforcing properties of cocaine-paired stimuli. Dorsal striatal DA transmission, in contrast, has been shown to be enhanced during cocaine seeking under a second-order schedule of reinforcement, which depends on the conditioned reinforcing properties of cocaine-associated stimuli. Therefore, the aim of the present study was to evaluate the role of DA and glutamate transmission in the dorsal striatum in cue-controlled cocaine seeking. Infusion of the DA receptor antagonist $\alpha$-flupenthixol into the dorsal striatum decreased cocaine seeking under a second-order schedule of reinforcement. In addition, intradorsal striatal infusion of the AMPA/kainate (KA) receptor antagonist LY293558 (3SR, 4aRS, 6RS, 8aRS-6-[2-(iH-tetrazol-5-yl)ethyl]-1,2,3,4,4a,5,6,7,8,8adecahydroiso-quinoline-3-carboxylic acid), but not the NMDA receptor antagonist AP-5, also decreased cue-controlled cocaine seeking. These data show that stimulation of DA and AMPA/KA receptors in the dorsal striatum is critical for well established drug seeking that depends on the reinforcing effects of cocaine-associated stimuli. In addition, given the importance of the dorsal striatum in stimulusresponse habit learning, these data suggest that the habitual or compulsive quality of persistent drug seeking depends on dorsal striatal mechanisms.

Key words: dorsal striatum; dopamine receptor; AMPA receptor; NMDA receptor; cocaine; reinforcement; second-order schedule; habit

\section{Introduction}

Drug-paired conditioned stimuli (CSs) can, as conditioned reinforcers, maintain drug seeking and precipitate drug craving and relapse (Stewart et al., 1984; Ehrman et al., 1992; Carter and Tiffany, 1999; Everitt and Robbins, 2000; Schindler et al., 2002; Panlilio et al., 2005). In rodents and primates, second-order schedules of reinforcement provide a well established method of investigating the neurobiology of drug seeking that is under the control of drug-associated CSs (Goldberg et al., 1975; Everitt and Robbins, 2000; Schindler et al., 2002). Indeed, cocaine seeking under a second-order schedule of reinforcement in humans shares many similarities to that observed in rats and monkeys (Panlilio et al., 2005).

Although the mesencephalic dopamine (DA) projection to the nucleus accumbens (NAcc) plays a pivotal role in the reinforcing effect of cocaine (Roberts et al., 1977; Pettit et al., 1984;

\footnotetext{
Received March 9, 2005; revised June 30, 2005; accepted Aug. 4, 2005.

This research was supported by a Medical Research Council (MRC) Programme Grant and was conducted within the Cambridge MRC Centre for Behavioral and Clinical Neuroscience. L.J.M.J.V. was a visiting scientist from the Research Institute Neurosciences Vrije Universiteit (Department of Medical Pharmacology, Vrije Universiteit Medical Center, Amsterdam, The Netherlands), supported by a Wellcome Trust Traveling Research Fellowship. We thank Caroline Parkinson, Mercedes Arroyo, and Rachel Underwood for skillful technical assistance. We also thank Eli Lilly and Dr. H.C. Fibiger for the generous gift of LY293558

Correspondence should be addressed to Louk J. M. J. Vanderschuren, Rudolf Magnus Institute of Neuroscience, Department of Pharmacology and Anatomy, University Medical Center Utrecht, Universiteitsweg 100, 3584 CG Utrecht, The Netherlands. E-mail: I.j.m.j.vanderschuren@med.uu.nl.

DOI:10.1523/JNEUROSCI.0925-05.2005

Copyright $\odot 2005$ Society for Neuroscience $\quad$ 0270-6474/05/258665-06\$15.00/0
}

Caine et al., 1995; Rodd-Henricks et al., 2002), this system appears not to mediate the conditioned reinforcing properties of cocaine-paired stimuli, because NAcc DA efflux is not correlated with responding for cocaine cues (Neisewander et al., 1996; Ito et al., 2000). Moreover, intra-NAcc infusion of a DA receptor antagonist did not alter cocaine seeking under a second-order schedule of reinforcement (Di Ciano and Everitt, 2004c), although infusion of an AMPA/kainate (KA) glutamate receptor antagonist did (Di Ciano and Everitt, 2001), suggesting that glutamatergic afferents to the NAcc, rather than NAcc DA, mediate the conditioned reinforcing effects of cocaine cues (Park et al., 2002).

In contrast, a clear DAergic correlate of cue-controlled cocaine seeking was seen in the dorsal striatum, in which DA efflux increased markedly in rats responding under a second-order schedule of reinforcement (Ito et al., 2002). The dorsal striatum has also been found to be activated during cue-elicited cocaine craving in humans (Garavan et al., 2000), and imaging studies in primates have shown that, with prolonged cocaine selfadministration, dorsal regions of the striatum become progressively more engaged by the drug (Letchworth et al., 2001; Porrino et al., 2004). It has also been shown that, after lengthy drug experience, drug seeking develops a habitual or compulsive quality (Deroche-Gamonet et al., 2004; Di Ciano and Everitt, 2004a; Vanderschuren and Everitt, 2004). In view of the role of the dorsal striatum in the establishment of stimulus-response (S-R) habits (Packard and Knowlton, 2002; White and McDonald, 
2002; Yin et al., 2004), these observations together suggest that the dorsal striatum mediates what has been hypothesized to be the habitual nature of well established drug seeking (Tiffany, 1990; Robbins and Everitt, 1999; Everitt et al., 2001). Therefore, in the present study, we investigated directly the role of the dorsal striatum in cue-controlled cocaine seeking by infusing the DA receptor antagonist $\alpha$-flupenthixol, the AMPA/KA receptor antagonist LY293558 (3SR, 4aRS, 6RS, 8aRS-6-[2-(iH-tetrazol5-yl)ethyl]-1,2,3,4,4a,5,6,7,8,8a-decahydroiso-quinoline-3-carboxylic acid), or the NMDA receptor antagonist AP-5 into the dorsal striatum in rats responding under a second-order schedule of reinforcement.

\section{Materials and Methods}

Animals. Adult male Lister Hooded rats (Charles River Laboratories, Kent, UK) weighing 300-350 $\mathrm{g}$ at the time of surgery were individually housed under a reversed $12 \mathrm{~h}$ light/dark cycle (lights on at 7:00 P.M.). On the day before the start of testing, rats were placed on a restricted diet of $20 \mathrm{~g} / \mathrm{d}$ lab chow (Purina), sufficient to maintain body weight and growth throughout the experiment. Water was available ad libitum, and food was given within $2 \mathrm{~h}$ after daily testing. Experiments were performed between 9:00 A.M. and 7:00 P.M., 5-6 d/week. Experiments were conducted in accordance with the United Kingdom 1986 Animals (Scientific Procedures) Act (Project License PPL 80/1324).

Apparatus. Rats were tested in operant chambers $(29.5 \times 32.5 \times 23.5$ cm; Med Associates, St. Albans, VT). Each chamber was equipped with two 4-cm-wide retractable levers. The two levers were $12 \mathrm{~cm}$ apart and 8 $\mathrm{cm}$ from the grid floor. Above each lever was a cue light $(2.5 \mathrm{~W}, 24 \mathrm{~V})$, and a red house light $(2.5 \mathrm{~W}, 24 \mathrm{~V})$ was located on the opposite wall. The floor of the chamber was covered with a metal grid. The testing chamber was placed within a sound- and light-attenuating box, equipped with a ventilation fan that also screened external noise. SILASTIC tubing shielded with a metal spring extended from each animal's intravenous catheter to a liquid swivel (Stoelting, Wood Dale, IL) mounted on an arm fixed outside of the operant chamber. Tygon tubing extended from the swivel to a Razel infusion pump (Semat Technical, Herts, UK) located adjacent to the external chamber. The operant chamber was controlled by software written by Rudolf Cardinal and Mike Aitken (University of Cambridge, Cambridge, UK) in the language $\mathrm{C}++$ using the Whisker control system (Cardinal and Aitken, 2001).

Intravenous surgery. Rats were anesthetized with ketamine hydrochloride $(100 \mathrm{mg} / \mathrm{kg}$, i.p.; Ketaset) and xylazine ( $9 \mathrm{mg} / \mathrm{kg}$, i.p.; Rompun), supplemented with ketamine as needed $(\sim 20 \mathrm{mg} / \mathrm{kg})$, and implanted with a single catheter in the right jugular vein. Catheters were made from 22 gauge cannulas with elongated ends. SILASTIC tubing (0.012 inner diameter) was secured to the bottom end of the cannula, and the top was fixed to nylon mesh. The mesh end of the catheter was sutured subcutaneously on the dorsum. All surgical instruments were thoroughly sterilized before surgery. To prevent infection, rats were treated postsurgically with $10 \mathrm{mg} / \mathrm{kg}$ Baytril (Bayer, Wuppertal, Germany) subcutaneously for 8 d. For details, see Caine et al. (1992).

Procedure. Daily experimental testing began 7-10 d after intravenous surgery. Active and inactive levers were counterbalanced between left and right sides for individual animals. "Priming" injections of cocaine were never given. During initial training, rats acquired a lever press response for cocaine $(0.25 \mathrm{mg} /$ infusion, $0.1 \mathrm{ml} / 5 \mathrm{~s})$ under a fixed-ratio (FR1) (timeout, $20 \mathrm{~s}$ ) schedule of reinforcement. On this schedule, each lever press resulted in illumination of the stimulus light above the lever, retraction of both levers, and extinction of the house light for $20 \mathrm{~s}$. After this $20 \mathrm{~s}$ interval, the house light was again illuminated, the stimulus light was extinguished, and the two levers were again inserted into the testing box. Presses on the inactive lever had no programmed consequences but were recorded to assess general levels of activity. After $3 \mathrm{~d}$ of stable responding on this schedule, a second-order schedule of the type FR $x$ (FR $y: S$ ) was gradually introduced, such that $x$ number of unit schedule requirements resulted in a cocaine infusion, and $y$ number of lever presses resulted in illumination of the stimulus light for $1 \mathrm{~s}$ within the unit schedule. Therefore, under a second-order schedule, rats were pre- sented with two stimuli: (1) a 1 s illumination of the stimulus light after $y$ responses, and (2) a 20 s illumination of the stimulus light during cocaine infusion. The schedule requirements were gradually increased, beginning with a value of $y$ set at 1 and a value of $x$ of 5 ; each lever press resulted in a $1 \mathrm{~s}$ CS presentation, and, after five such CS presentations, rats received a cocaine infusion and associated $20 \mathrm{~s}$ presentation of this stimulus light. Subsequently, the response requirements increased to FR10 (FR1:S), FR10(FR2:S), FR10(FR4:S), FR10(FR7:S), and FR10(FR10:S). After stable responding under the final schedule, a fixed-interval (FI) [FI15 $\min ($ FR10:S)] schedule was introduced, and rats were allowed to stabilize and establish individual patterns of responding under this schedule. Under this schedule, cocaine was available after completion of an FR of 10 responses after an overall FI 15 min had timed out; during the FI 15 min, each FR10 response was reinforced by presentation of the drug-paired CS. Animals were permitted five infusions of cocaine per day under this schedule.

Intracranial surgery and microinfusions. After the acquisition of stable responding under an FI15(FR10:S) schedule, rats were anesthetized with ketamine hydrochloride ( $100 \mathrm{mg} / \mathrm{kg}$, i.p.; Ketaset) and xylazine $(9 \mathrm{mg} / \mathrm{kg}$, i.p.; Rompun) and positioned into a stereotaxic frame (David Kopf Instruments, Tujunga, CA). Guide cannulas, consisting of 24 gauge thinwalled stainless steel tubing (Cooper's Needleworks), were implanted bilaterally, aimed $2.0 \mathrm{~mm}$ above the dorsal striatum [+1.2 $\mathrm{mm}$ anteroposterior; $\pm 3.0 \mathrm{~mm}$ mediolateral; $-3.0 \mathrm{~mm}$ dorsoventral; incisor bar at $-3.3 \mathrm{~mm}$ (Paxinos and Watson, 1986)]. Cannulas were secured with stainless steel screws and dental acrylic; 29 gauge wire stylets (Cooper's Needleworks) were inserted into the guide cannulas to maintain patency. After reacquisition of stable responding under an FI15(FR10:S) schedule of reinforcement, intracerebral microinfusions $(0.5 \mu \mathrm{l})$ were made through a 28 gauge injector (Semat Technical) lowered to the site of injection $(-5.0 \mathrm{~mm})$ over $90 \mathrm{~s}$ simultaneously to both sides of the brain using a syringe pump (model 975A; Harvard Apparatus, Holliston, MA), followed by a $60 \mathrm{~s}$ postinfusion diffusion time. After all infusions, stylets were replaced, and the animal was left in a holding box for $5 \mathrm{~min}$ before testing. Before drug infusions and behavioral assessment, all rats received one or two infusions of phosphate buffer on separate days to habituate them to the injection procedure. Intracerebral infusions of the DA receptor antagonist $\alpha$-flupenthixol (Sigma, Poole, UK), the AMPA/KA antagonist LY293558 (a gift from Eli Lilly \& Co., Indianapolis, IN), and the NMDA receptor antagonist AP-5 (Sigma) were given after at least $2 \mathrm{~d}$ of stable responding subsequent to the phosphate buffer infusions. $\alpha$-Flupenthixol was dissolved in distilled water, and LY293558 and AP-5 were dissolved in phosphate-buffered water (composition of $0.07 \mathrm{~mm}$ $\mathrm{Na}_{2} \mathrm{HPO}_{4}$ and $0.028 \mathrm{~mm} \mathrm{NaH}_{2} \mathrm{PO}_{4}$, giving an approximate $\mathrm{pH}$ of 7.5). AP-5 was given in a single dose $(2 \mu \mathrm{g} / \mathrm{side})$, and $\alpha$-flupenthixol $(5,10$, and $15 \mu \mathrm{g} / \mathrm{side})$ and $\operatorname{LY} 293558(0.05,0.1$, and $0.2 \mu \mathrm{g} / \mathrm{side})$ were given in three doses plus vehicle, according to a counterbalanced, Latin square design (Keppel, 1991), with infusions of each dose being separated by at least $2 \mathrm{~d}$ of stable responding without treatment. After completion of the $\alpha$-flupenthixol dose-effect study, six rats were shifted back to an FR1 (timeout, $20 \mathrm{~s}$ ) schedule of reinforcement. In these animals, the effect of $\alpha$-flupenthixol (10 and $15 \mu \mathrm{g} / \mathrm{side}$ ) on cocaine self-administration were assessed in $2 \mathrm{~h}$ sessions during which every lever press resulted in a cocaine infusion. Drug doses were based on previous studies in our laboratory (Di Ciano and Everitt, 2001, 2004c; Di Ciano et al., 2001).

Histological assessment of cannulas placements. At the end of testing, rats were anesthetized with an overdose of sodium pentobarbitone (1.5 $\mathrm{ml} /$ animal, i.p., Euthatal; Rhône-Mérieux, Hertfordshire, UK) and perfused transcardially with isotonic saline, followed by $4 \%$ paraformaldehyde in $0.2 \mathrm{M}$ phosphate buffer. Brains were then removed and postfixed before being transferred to a $20 \%$ sucrose solution in $0.01 \mathrm{~m}$ PBS for $\sim 24$ $\mathrm{h}$ before being sectioned at $60 \mu \mathrm{m}$ using a freezing microtome. Every third section was mounted and stained with cresyl violet, and placements were verified under a light microscope.

Statistical analyses. For all self-administration sessions, the number of active and inactive lever presses was recorded. For the second-order schedule of self-administration, lever presses for the first $15 \mathrm{~min}$ interval, when rats were responding for cocaine CSs while in a drug-free condition, are presented as the mean \pm SEM number of responses. For the FR1 


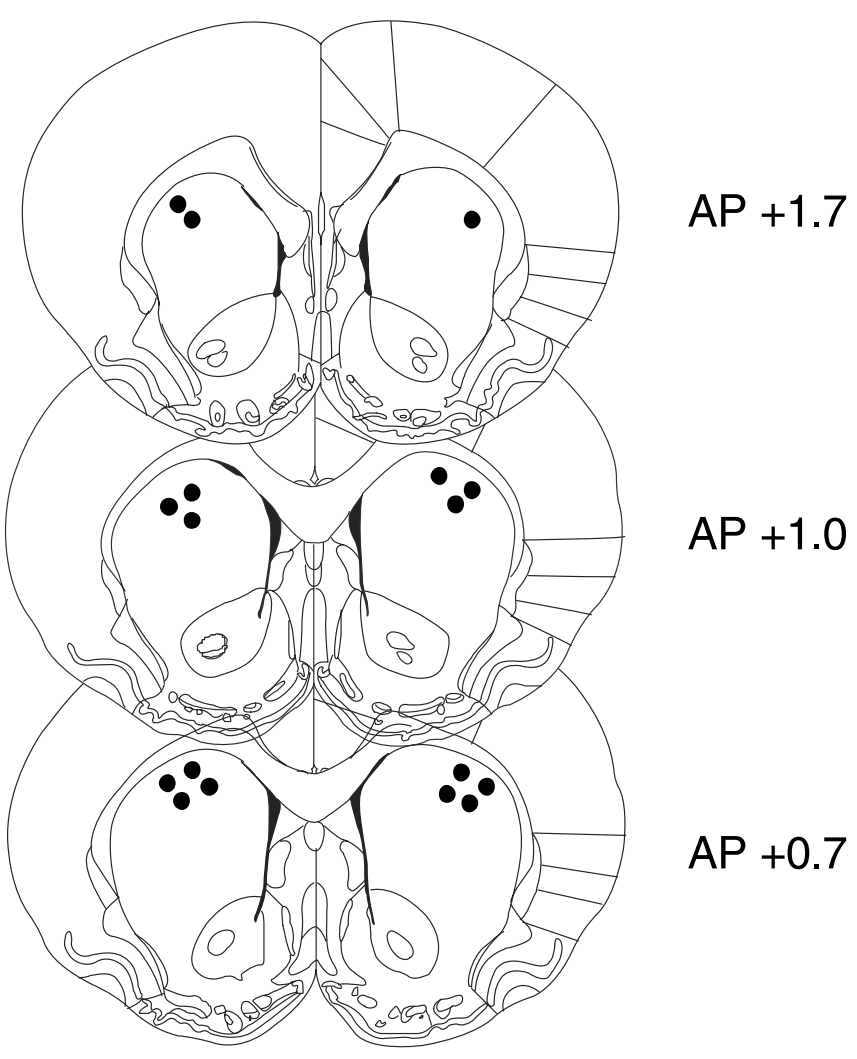

Figure 1. Location of the tips of injection cannulas within the dorsal striatum (filled circles; $n=13$ ). Distances are in millimeters from bregma (adapted from Paxinos and Watson, 1986). AP, Anteroposterior.

schedule, total number of active and inactive presses during the $2 \mathrm{~h}$ session are presented as mean \pm SEM number of responses. All measures were analyzed with repeated-measures ANOVA for drug dose. When appropriate, post hoc comparisons were made using Student-NewmanKeuls tests.

\section{Results}

\section{Histology}

Figure 1 shows the location of the tips of injection cannulas within the dorsolateral striatum (filled circles; $n=13$ ) established by microscopical examination of cresyl violet-stained coronal sections of the brain by an observer blind to the behavioral results. No animals were discarded from the analysis because of cannula misplacements.

\section{Second-order schedule of cocaine self-administration $\alpha$-Flupenthixol}

Infusion of $\alpha$-flupenthixol into the dorsal striatum resulted in a significant, dose-dependent suppression of responding on the active lever during the first $15 \mathrm{~min}$ interval of the session $\left(F_{(3,21)}=\right.$ 4.05; $p<0.05)$. Post hoc comparisons revealed that $15 \mu \mathrm{g}$ of $\alpha$-flupenthixol significantly decreased the number of responses made (Fig. 2, left). The number of inactive lever presses was not affected by $\alpha$-flupenthixol $\left(F_{(3,21)}=2.71\right.$; NS) (Fig. 2, right). Under an FR1 schedule of reinforcement, $\alpha$-flupenthixol at 10 and $15 \mu \mathrm{g}$ significantly increased the number of active lever presses (vehicle, $42.2 \pm 5.6 ; 10 \mu \mathrm{g}$ of $\alpha$-flupenthixol, $61.7 \pm 6.2$; $15 \mu \mathrm{g}$ of $\alpha$-flupenthixol, $\left.67.5 \pm 2.9 ; F_{(2,10)}=23.23 ; p<0.001\right)$ but did not alter the number of inactive presses (vehicle, $1.5 \pm$ 1.5; $10 \mu \mathrm{g}$ of $\alpha$-flupenthixol, $0.8 \pm 0.7 ; 15 \mu \mathrm{g}$ of $\alpha$-flupenthixol, $\left.3.2 \pm 2.0 ; F_{(2,10)}=2.71 ; \mathrm{NS}\right)$. active lever presses

inactive lever presses
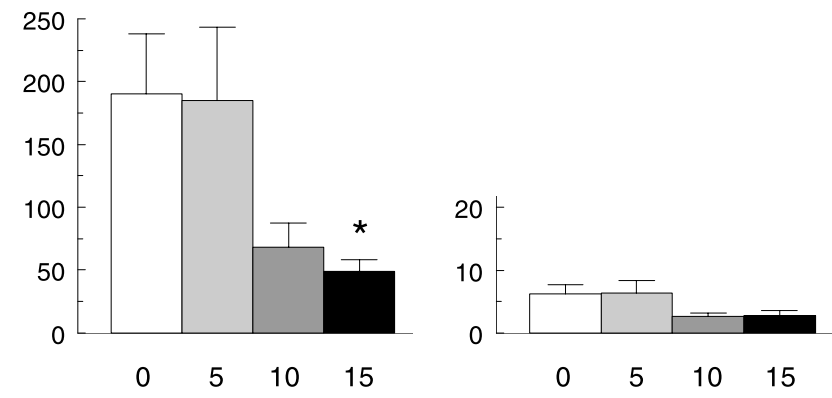

dose of alpha-flupenthixol (microgram/side)

Figure 2. Effects of the DA receptor antagonist $\alpha$-flupenthixol on self-administration of cocaine under a second-order schedule of reinforcement. Left, $\alpha$-Flupenthixol infusion into the dorsal striatum decreased the number of active responses in the first, drug-free interval. Right, After infusion in the dorsal striatum, $\alpha$-flupenthixol did not influence inactive lever presses. Data are presented as mean \pm SEM responses during the first $15 \mathrm{~min}$ interval of the session. ${ }^{*} p<0.05$, different from vehicle (Student-Newman-Keuls test). active lever presses

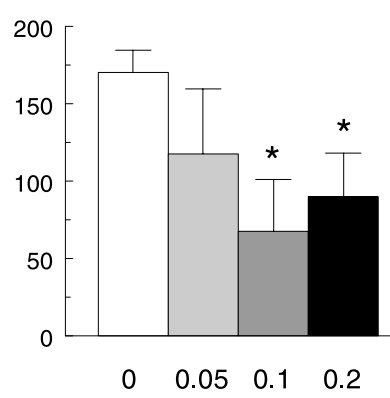

dose of LY293558 (microgram/side)
Figure 3. Effects of the AMPA/KA receptor antagonist LY293558 on self-administration of cocaine under a second-order schedule of reinforcement. Left, LY293558 infusion into the dorsal striatum decreased the number of active lever presses in the first, drug-free interval. Right, LY293558 into the dorsal striatum did not affect the number of inactive responses. Data are presented as mean \pm SEM responses during the first 15 min interval of the session. ${ }^{*} p<0.05$, different from vehicle (Student-Newman-Keuls test).

\section{LY293558}

After infusion of LY293558 into the dorsal striatum, the number of active responses was decreased $\left(F_{(3,12)}=3.58 ; p<0.05\right)$ to a level that was significantly different from vehicle at doses of 0.1 and $0.2 \mu \mathrm{g} / \mathrm{side}$ (Fig. 3, left). Analysis of the number of inactive lever presses revealed no effect of LY293558 $\left(F_{(3,12)}=1.94\right.$; NS) (Fig. 3, right).

AP-5

Infusion of AP-5 into the dorsal striatum was without effect on responding on the active lever (vehicle, $180.0 \pm 10.5$ responses; AP-5, 205.3 \pm 90.3 responses; $F_{(1,3)}=0.10$; NS) or on the inactive lever (vehicle, $4.8 \pm 2.5$ responses; AP-5, $9.8 \pm 2.1$ responses; $F_{(1,3)}=2.63$; NS).

\section{Discussion}

The results of the present study show that blockade of DA or AMPA/KA receptors in the dorsal striatum inhibits cocaine seeking underpinned by response-contingent presentations of drugpaired CSs in rats (Everitt and Robbins, 2000). These findings 
may have considerable implications for our understanding of the psychobiology of drug addiction.

Mesostriatal DA neurons are known to be activated by reward-predictive CSs (Schultz, 2002), and noncontingent, pavlovian presentation of cocaine cues has been shown to increase NAcc DA efflux (Gratton and Wise, 1994; Kiyatkin and Stein, 1996; Duvauchelle et al., 2000; Ito et al., 2000; Weiss et al., 2000; Phillips et al., 2003) (but see Brown and Fibiger, 1992; Bradberry et al., 2000). However, DA efflux in the NAcc is not altered during cocaine seeking when cocaine-associated CSs are presented contingent on responding (Neisewander et al., 1996; Ito et al., 2000). These observations are consistent with our previous findings that the integrity of the NAcc DA innervation is not critical for responding with conditioned reinforcement but is required for the potentiation of conditioned reinforcement by psychostimulant drugs (Taylor and Robbins, 1986; Wolterink et al., 1993). In contrast, responding for cocaine under a second-order schedule of reinforcement is accompanied by enhanced DA efflux in the dorsal striatum (Ito et al., 2002), and infusion of a DA receptor antagonist into the dorsal striatum, but not the NAcc, reduced cocaine-seeking under a second-order schedule of reinforcement (Di Ciano and Everitt, 2004c; present study). Thus, the present data add to the evidence suggesting that the way in which cocaine-associated CSs are presented (contingent or noncontingent) determines whether DA neurons projecting to NAcc or dorsal striatum are activated.

Unlike NAcc DA, NAcc AMPA/KA receptor-mediated glutamate neurotransmission has been implicated in cue-controlled cocaine seeking. Glutamate efflux in the NAcc has been found to increase when animals are exposed to a cocaine-paired environment (Hotsenpiller et al., 2001), and intra-NAcc administration of an AMPA/KA antagonist attenuates the expression of cocaine conditioned place preference (Kaddis et al., 1995), cocaine seeking under a second-order schedule of reinforcement (Di Ciano and Everitt, 2001, 2004c), and cocaine-primed reinstatement of responding for cocaine cues (Park et al., 2002). The present study provides direct evidence that dorsal striatal glutamate, through stimulation of AMPA/KA receptors, is also important for the performance of cocaine seeking supported by cocaine-associated conditioned reinforcers.

It is unlikely that the effects of $\alpha$-flupenthixol or LY293558 on responding for cocaine cues were secondary to changes in locomotor activity. There were no effects of $\alpha$-flupenthixol or LY293558 on inactive lever presses. In addition, intradorsal striatum infusion of $\alpha$-flupenthixol did not suppress, but dose dependently increased, lever pressing for cocaine under an FR1 schedule. These results suggest that DA receptor blockade in this dorsal striatal region attenuates the primary reinforcing effect of cocaine, which seems inconsistent with previous findings (Caine et al., 1995; Ikemoto, 2003), although different areas within the dorsal striatum were targeted in these studies. Thus, a specific domain within the dorsal striatum may contribute to the reinforcing effects of cocaine.

Blockade of DA and AMPA/KA receptors in the dorsal striatum disrupted cocaine seeking under a second-order schedule of reinforcement. However, the majority of studies investigating the neural basis of this behavior, as well as the cued reinstatement of extinguished cocaine seeking, have demonstrated a dependence on limbic cortical-ventral striatal circuitry, including the ventral tegmental area (VTA), amygdala, prefrontal cortex, and NAcc (Whitelaw et al., 1996; Meil and See, 1997; Weissenborn et al., 1997; Di Ciano and Everitt, 2001, 2004b; Park et al., 2002; McLaughlin and See, 2003; Fuchs et al., 2004). However, the DAergic innervation of the dorsolateral striatum targeted here arises primarily from the substantia nigra pars compacta rather than the VTA (Fallon and Moore, 1978; Gerfen et al., 1987; Oades and Halliday, 1987; Voorn et al., 2004). Moreover, this region of the dorsal striatum predominantly receives glutamatergic projections from sensorimotor cortex and central lateral thalamus but less so from prefrontal cortex, basolateral amygdala, or hippocampus (Kelley et al., 1982; Groenewegen et al., 1987; McGeorge and Faull, 1989; McDonald, 1991; Voorn et al., 2004). Therefore, our data indicate that the neural systems underlying well established cue-controlled cocaine seeking are more extensive than usually considered.

The behavior of animals responding for a first infusion of cocaine under a second-order schedule of reinforcement is controlled by the conditioned reinforcing properties of the cocaineassociated CS as well as anticipation of drug reinforcement (for review, see Everitt and Robbins, 2000). Because responding during this period of time occurs in a drug-free state, the effect of $\alpha$-flupenthixol on cue-controlled cocaine seeking cannot be the result of any effect on the reinforcing properties of cocaine itself. In addition, dopaminergic lesions of the dorsal striatum or infusions of D-amphetamine into the dorsolateral striatum have no effect on the acquisition of responding for conditioned reinforcement or its potentiation by psychostimulant drugs (Taylor and Robbins, 1984, 1986; Kelley and Delfs, 1991). Rather, the dorsal striatum (Packard and McGaugh, 1996; Yin et al., 2004) including its dopaminergic (Robbins et al., 1990; Packard and White, 1991) and glutamatergic (Packard, 1999) innervation has been shown to be involved in the acquisition of S-R habits, whereby behavior becomes automatic and relatively independent of the goal: that is, it is no longer driven by an action-outcome relationship (for review, see Everitt et al., 2001; Packard and Knowlton, 2002; White and McDonald, 2002). The present findings therefore suggest that the performance of cocaine seeking as studied here may reflect the establishment of a habitual form of responding that depends on dorsal striatal processes.

Although the dorsal striatum plays a role in the performance of well established cocaine seeking, it is the ventral striatum, including the nucleus accumbens shell and the olfactory tubercle, that has been shown to be important for the initial acquisition of cocaine self-administration (Rodd-Henricks et al., 2002; Ikemoto, 2003). The nucleus accumbens core, in turn, is required for the acquisition of cocaine seeking under a second-order schedule of reinforcement (Ito et al., 2004). This apparently progressive involvement of dorsal striatal-dependent processes has also been revealed in metabolic and molecular imaging studies of primates with a prolonged history of cocaine self-administration. Thus, when comparing dopamine transporter binding or metabolic activity after 5 or 100 sessions of cocaine self-administration, it was shown that changes that were restricted to the ventral striatum early on, spread dorsally to involve the dorsal striatum, including the sensorimotor striatal domains studied here, at the chronic stage (Letchworth et al., 2001; Porrino et al., 2004). This ventralto-dorsal intrastriatal progression of regions engaged by the selfadministration of cocaine may be subserved by striato-VTA/ nigro-striatal pathways, whereby ventral striatal regions influence not only their own DAergic innervation but also that of progressively more dorsal areas via their spiraling projections to DA neurons in the VTA and substantia nigra (Haber et al., 2000). In this way, cocaine-induced increases in DA in the NAcc shell can modulate DAergic activity not only in the core but also in more dorsal associative and sensorimotor domains of the striatum. This mechanism strengthens the longer the history of cocaine self-administration. 
We have hypothesized that, over the course of many cycles of drug self-administration, the associative structure underlying drug seeking may reflect a shift from a goal-directed responseoutcome process mediated by the ventral striatum to one dominated by a habitual, stimulus-response form of behavior that depends on the dorsal striatum (Tiffany, 1990; Robbins and Everitt, 1999; Everitt et al., 2001). This is not to imply that limbic cortical-ventral striatal mechanisms no longer contribute to cocaine seeking when well established, because we have shown that AMPA/KA receptor blockade in the NAcc core as well as DA receptor blockade in the basolateral amygdala attenuate the performance of cocaine seeking (Di Ciano and Everitt, 2001, 2004c). The NAcc core clearly mediates conditioned influences on instrumental behavior (Parkinson et al., 1999; Corbit et al., 2001; Hall et al., 2001; Ito et al., 2004) and is also critical for animals to tolerate delays to reinforcement (Cardinal et al., 2001) which are inherent in second-order schedules of reinforcement (Everitt and Robbins, 2000). We therefore hypothesize that DAergic mechanisms in the NAcc shell and core that mediate reinforcement processes and modulate limbic cortical mechanisms controlling goal-directed behavior progressively activate, consolidate, and may eventually become subordinate to a dorsal striatumdependent habit system (Everitt et al., 2001; Porrino et al., 2004). This may explain the powerful impact that drug-associated conditioned reinforcers have on drug seeking: they support the acquisition of this behavior, helping animals and humans to bridge often long delays to primary drug reinforcement, but they also progressively engage a dorsal striatal mechanism through which responding becomes automatic. In support of this hypothesis, we have shown that rats not only readily acquire a new response reinforced by presentations of a cocaine-associated CS but also that, once acquired, responding for the conditioned reinforcer is resistant to extinction and persists for many weeks, even in the absence of additional pairings with cocaine (Weiss et al., 2001; Di Ciano and Everitt, 2004a). Thus, the neural plasticity mechanisms that are engaged by self-administered cocaine and other addictive drugs (Nestler, 2001; Kauer, 2004; Kelley, 2004) not only underlie alterations in incentive motivational or reward systems (Robinson and Berridge, 1993; Wise, 2004) but also in the associative structures underlying persistent drug seeking (Robbins and Everitt, 1999; Everitt et al., 2001).

\section{References}

Bradberry CW, Barrett-Larimore RL, Jatlow P, Rubino SR (2000) Impact of self-administered cocaine and cocaine cues on extracellular dopamine in mesolimbic and sensorimotor striatum in rhesus monkeys. J Neurosci 20:3874-3883.

Brown EE, Fibiger HC (1992) Cocaine-induced conditioned locomotion: absence of associated increases in dopamine release. Neuroscience 48:621-629.

Caine SB, Lintz R, Koob GF (1992) Intravenous self-administration techniques in animals. In: Behavioral neuroscience: a practical approach (Sahgal A, ed), pp 117-143. Oxford: Oxford UP.

Caine SB, Heinrichs SC, Coffin VL, Koob GF (1995) Effects of the dopamine D-1 antagonist SCH 23390 microinjected into the accumbens, amygdala or striatum on cocaine self-administration in the rat. Brain Res 692:47-56.

Cardinal RN, Aitken MRF (2001) Whisker, version 2.2, computer software, http://www. whiskercontrol.com.

Cardinal RN, Pennicott DR, Sugathapala CL, Robbins TW, Everitt BJ (2001) Impulsive choice induced in rats by lesions of the nucleus accumbens core. Science 292:2499-2501.

Carter BL, Tiffany ST (1999) Meta-analysis of cue-reactivity in addiction research. Addiction 94:327-340.

Corbit LH, Muir JL, Balleine BW (2001) The role of the nucleus accumbens in instrumental conditioning: evidence of a functional dissociation between accumbens core and shell. J Neurosci 21:3251-3260.
Deroche-Gamonet V, Belin D, Piazza PV (2004) Evidence for addiction-like behavior in the rat. Science 305:1014-1017.

Di Ciano P, Everitt BJ (2001) Dissociable effects of antagonism of NMDA and AMPA/KA receptors in the nucleus accumbens core and shell on cocaine-seeking behavior. Neuropsychopharmacology 25:341-360.

Di Ciano P, Everitt BJ (2004a) Conditioned reinforcing properties of stimuli paired with self-administered cocaine, heroin or sucrose: implications for the persistence of addictive behaviour. Neuropharmacology 47 [Suppl 1]:202-213.

Di Ciano P, Everitt BJ (2004b) Contribution of the ventral tegmental area to cocaine-seeking maintained by a drug-paired conditioned stimulus in rats. Eur J Neurosci 19:1661-1667.

Di Ciano P, Everitt BJ (2004c) Direct interactions between the basolateral amygdala and nucleus accumbens core underlie cocaine-seeking behavior by rats. J Neurosci 24:7167-7173.

Di Ciano P, Cardinal RN, Cowell RA, Little SJ, Everitt BJ (2001) Differential involvement of NMDA, AMPA/kainate, and dopamine receptors in the nucleus accumbens core in the acquisition and performance of pavlovian approach behavior. J Neurosci 21:9471-9477.

Duvauchelle CL, Ikegami A, Castaneda E (2000) Conditioned increases in behavioral activity and accumbens dopamine levels produced by intravenous cocaine. Behav Neurosci 114:1156-1166.

Ehrman RN, Robbins SJ, Childress AR, O’Brien CP (1992) Conditioned responses to cocaine-related stimuli in cocaine abuse patients. Psychopharmacology 107:523-529.

Everitt BJ, Robbins TW (2000) Second-order schedules of drug reinforcement in rats and monkeys: measurement of reinforcing efficacy and drugseeking behaviour. Psychopharmacology 153:17-30.

Everitt BJ, Dickinson A, Robbins TW (2001) The neuropsychological basis of addictive behaviour. Brain Res Brain Res Rev 36:129-138.

Fallon JH, Moore RY (1978) Catecholamine innervation of the basal forebrain. IV. Topography of the dopamine projection to the basal forebrain and neostriatum. J Comp Neurol 180:545-580.

Fuchs RA, Evans KA, Parker MC, See RE (2004) Differential involvement of the core and shell subregions of the nucleus accumbens in conditioned cue-induced reinstatement of cocaine seeking in rats. Psychopharmacology 176:459-465.

Garavan H, Pankiewicz J, Bloom A, Cho JK, Sperry L, Ross TJ, Salmeron BJ, Risinger R, Kelley D, Stein EA (2000) Cue-induced cocaine craving: neuroanatomical specificity for drug users and drug stimuli. Am J Psychiatry 157:1789-1798.

Gerfen CR, Herkenham M, Thibault J (1987) The neostriatal mosaic. II. Patch- and matrix-directed mesostriatal dopaminergic and nondopaminergic systems. J Neurosci 7:3915-3934.

Goldberg SR, Kelleher RT, Morse WH (1975) Second-order schedules of drug injection. Fed Proc 34:1771-1776.

Gratton A, Wise RA (1994) Drug- and behavior-associated changes in dopamine-related electrochemical signals during intravenous cocaine self-administration in rats. J Neurosci 14:4130-4146.

Groenewegen HJ, Vermeulen-Van der Zee E, te Kortschot A, Witter MP (1987) Organization of the projections from the subiculum to the ventral striatum in the rat. A study using anterograde transport of Phaseolus vulgaris leucoagglutinin. Neuroscience 23:103-120.

Haber SN, Fudge JL, McFarland NR (2000) Striatonigrostriatal pathways in primates form an ascending spiral from the shell to the dorsolateral striatum. J Neurosci 20:2369-2382.

Hall J, Parkinson JA, Connor TM, Dickinson A, Everitt BJ (2001) Involvement of the central nucleus of the amygdala and nucleus accumbens core in mediating pavlovian influences on instrumental behavior. Eur J Neurosci 13:1984-1992.

Hotsenpiller G, Giorgetti M, Wolf ME (2001) Alterations in behaviour and glutamate transmission following presentation of stimuli previously associated with cocaine exposure. Eur J Neurosci 14:1843-1855.

Ikemoto S (2003) Involvement of the olfactory tubercle in cocaine reward: intracranial self-administration studies. J Neurosci 23:9305-9311.

Ito R, Dalley JW, Howes SR, Robbins TW, Everitt BJ (2000) Dissociation in conditioned dopamine release in the nucleus accumbens core and shell in response to cocaine cues and during cocaine-seeking behavior in rats. J Neurosci 20:7489-7495.

Ito R, Dalley JW, Robbins TW, Everitt BJ (2002) Dopamine release in the dorsal striatum during cocaine-seeking behavior under the control of a drug-associated cue. J Neurosci 22:6247-6253. 
Ito R, Robbins TW, Everitt BJ (2004) Differential control over cocaineseeking behavior by nucleus accumbens core and shell. Nat Neurosci 7:389-397.

Kaddis FG, Uretsky NJ, Wallace LJ (1995) DNQX in the nucleus accumbens inhibits cocaine-induced conditioned place preference. Brain Res 697:76-82.

Kauer JA (2004) Learning mechanisms in addiction: synaptic plasticity in the ventral tegmental area as a result of exposure to drugs of abuse. Annu Rev Physiol 66:447-475.

Kelley AE (2004) Memory and addiction; shared neural circuitry and molecular mechanisms. Neuron 44:161-179.

Kelley AE, Delfs JM (1991) Dopamine and conditioned reinforcement. I. Differential effects of amphetamine microinjections into striatal subregions. Psychopharmacology 103:187-196.

Kelley AE, Domesick VB, Nauta WJH (1982) The amygdalostriatal projection in the rat - an anatomical study by anterograde and retrograde tracing methods. Neuroscience 7:615-630.

Keppel G (1991) Design and analysis. A researcher's handbook. Englewood Cliffs, NJ: Prentice Hall.

Kiyatkin EA, Stein EA (1996) Conditioned changes in nucleus accumbens dopamine signal established by intravenous cocaine in rats. Neurosci Lett 211:73-76.

Letchworth SR, Nader MA, Smith HR, Friedman DP, Porrino LJ (2001) Progression of changes in dopamine transporter binding site density as a result of cocaine self-administration in rhesus monkeys. J Neurosci 21:2799-2807.

McDonald AJ (1991) Topographical organization of amygdaloid projections to the caudatoputamen, nucleus accumbens, and related striatal-like areas of the rat brain. Neuroscience 44:15-33.

McGeorge AJ, Faull RLM (1989) The organization of the projection from the cerebral cortex to the striatum in the rat. Neuroscience 29:503-537.

McLaughlin J, See RE (2003) Selective inactivation of the dorsomedial prefrontal cortex and the basolateral amygdala attenuates conditioned-cued reinstatement of extinguished cocaine-seeking behavior in rats. Psychopharmacology 168:57-65.

Meil WM, See RE (1997) Lesions of the basolateral amygdala abolish the ability of drug associated cues to reinstate responding during withdrawal from self-administered cocaine. Behav Brain Res 87:139-148.

Neisewander JL, O’Dell LE, Tran-Nguyen LTL, Castañeda E, Fuchs RA (1996) Dopamine overflow in the nucleus accumbens during extinction and reinstatement of cocaine self-administration behavior. Neuropsychopharmacology 15:506-514.

Nestler EJ (2001) Molecular basis of long-term plasticity underlying addiction. Nat Rev Neurosci 2:119-128.

Oades RD, Halliday GM (1987) Ventral tegmental (A10) system: neurobiology. 1. Anatomy and connectivity. Brain Res Rev 12:117-165.

Packard MG (1999) Glutamate infused posttraining into the hippocampus or caudate-putamen differentially strengthens place and response learning. Proc Natl Acad Sci USA 96:12881-12886.

Packard MG, McGaugh JL (1996) Inactivation of hippocampus or caudate nucleus with lidocaine differentially affects expression of place and response learning. Neurobiol Learn Mem 65:65-72.

Packard MG, Knowlton BJ (2002) Learning and memory functions of the basal ganglia. Annu Rev Neurosci 25:563-593.

Packard MG, White NM (1991) Dissociation of hippocampus and caudate nucleus memory systems by posttraining intracerebral injection of dopamine agonists. Behav Neurosci 105:295-306.

Panlilio LV, Yasar S, Nemeth-Coslett R, Katz JL, Henningfield JE, Solinas M, Heishman SJ, Schindler CW, Goldberg SR (2005) Human cocaineseeking behavior and its control by drug-associated stimuli in the laboratory. Neuropsychopharmacology 30:433-443.

Park W-K, Bari AA, Jey AR, Spealman RD, Rowlett JK, Pierce RC (2002) Cocaine administered into the medial prefrontal cortex reinstates cocaine-seeking behavior by increasing AMPA receptor-mediated glutamate transmission in the nucleus accumbens. J Neurosci 22:2916-2925.

Parkinson JA, Olmstead MC, Burns LH, Robbins TW, Everitt BJ (1999) Dissociation in effects of lesions of the nucleus accumbens core and shell on appetitive pavlovian approach behavior and the potentiation of conditioned reinforcement and locomotor activity by D-amphetamine. J Neurosci 19:2401-2411.

Paxinos G, Watson C (1986) The rat brain in stereotaxic coordinates. Orlando, FL: Academic.
Pettit HO, Ettenberg A, Bloom FE, Koob GF (1984) Destruction of dopamine in the nucleus accumbens selectively attenuates cocaine but not heroin self-administration in rats. Psychopharmacology 84:167-173.

Phillips PEM, Stuber GD, Heien MLAV, Wightman RM, Carelli RM (2003) Subsecond dopamine release promotes cocaine seeking. Nature 422:614-618.

Porrino LJ, Lyons D, Smith HR, Daunais JB, Nader MA (2004) Cocaine self-administration produces a progressive involvement of limbic, association, and sensorimotor striatal domains. J Neurosci 24:3554-3562.

Robbins TW, Everitt BJ (1999) Drug addiction: bad habits add up. Nature 398:567-570.

Robbins TW, Giardini V, Jones GH, Reading P, Sahakian BJ (1990) Effects of dopamine depletion from the caudate-putamen and nucleus accumbens septi on the acquisition and performance of a conditional discrimination task. Behav Brain Res 38:243-261.

Roberts DCS, Corcoran ME, Fibiger HC (1977) On the role of ascending catecholaminergic systems in intravenous self-administration of cocaine. Pharmacol Biochem Behav 6:615-620.

Robinson TE, Berridge KC (1993) The neural basis of drug craving: an incentive-sensitization theory of addiction. Brain Res Brain Res Rev 18:247-291.

Rodd-Henricks ZA, McKinzie DL, Li TK, Murphy JM, McBride WJ (2002) Cocaine is self-administered into the shell but not the core of the nucleus accumbens of Wistar rats. J Pharmacol Exp Ther 303:1216-1226.

Schindler CW, Panlilio LV, Goldberg SR (2002) Second-order schedules of drug self-administration in animals. Psychopharmacology 163:327-344.

Schultz W (2002) Getting formal with dopamine and reward. Neuron $36: 241-263$.

Stewart J, De Wit H, Eikelboom R (1984) Role of unconditioned and conditioned drug effects in the self-administration of opiates and stimulants. Psychol Rev 91:251-268.

Taylor JR, Robbins TW (1984) Enhanced behavioural control by conditioned reinforcers following microinjections of $d$-amphetamine into the nucleus accumbens. Psychopharmacology 84:405-412.

Taylor JR, Robbins TW (1986) 6-Hydroxydopamine lesions of the nucleus accumbens, but not of the caudate nucleus, attenuate enhanced responding with reward-related stimuli produced by intra-accumbens $d$-amphetamine. Psychopharmacology 90:390-397.

Tiffany ST (1990) A cognitive model of drug urges and drug-use behavior: role of automatic and nonautomatic processes. Psychol Rev 97:147-168.

Vanderschuren LJMJ, Everitt BJ (2004) Drug seeking becomes compulsive after prolonged cocaine self-administration. Science 305:1017-1019.

Voorn P, Vanderschuren LJMJ, Groenewegen HJ, Robbins TW, Pennartz CMA (2004) Putting a spin on the dorsal-ventral divide of the striatum. Trends Neurosci 27:468-474.

Weiss F, Maldonado-Vlaar CS, Parsons LH, Kerr TM, Smith DL, Ben-Shahar O (2000) Control of cocaine-seeking behavior by drug-associated stimuli in rats: effects on recovery of extinguished operant-responding and extracellular dopamine levels in amygdala and nucleus accumbens. Proc Natl Acad Sci USA 97:4321-4326.

Weiss F, Martin-Fardon R, Ciccocioppo R, Kerr TM, Smith DL, Ben-Shahar $\mathrm{O}$ (2001) Enduring resistance to extinction of cocaine-seeking behavior induced by drug-related cues. Neuropsychopharmacology 25:361-372.

Weissenborn R, Robbins TW, Everitt BJ (1997) Effects of medial prefrontal or anterior cingulate cortex lesions on responding for cocaine under fixed-ratio and second-order schedules of reinforcement in rats. Psychopharmacology 134:242-257.

White NM, McDonald RJ (2002) Multiple parallel memory systems in the brain of the rat. Neurobiol Learn Mem 77:125-184.

Whitelaw RB, Markou A, Robbins TW, Everitt BJ (1996) Excitotoxic lesions of the basolateral amygdala impair the acquisition of cocaine-seeking behaviour under a second-order schedule of reinforcement. Psychopharmacology 127:213-224.

Wise RA (2004) Dopamine, learning and motivation. Nat Rev Neurosci 5:483-494.

Wolterink G, Phillips G, Cador M, Donselaar-Wolterink I, Robbins TW, Everitt BJ (1993) Relative roles of ventral striatal D1 and D2 dopamine receptors in responding with conditioned reinforcement. Psychopharmacology 110:355-364.

Yin HH, Knowlton BJ, Balleine BW (2004) Lesions of the dorsolateral striatum preserve outcome expectancy but disrupt habit formation in instrumental learning. Eur J Neurosci 19:181-189. 